\title{
A EDUCAÇÃO ESCOLAR INDÍGENA NO PARANÁ 1
}

Kimiye Tommasino

Professora aposentada da Universidade Estadual de Londrina

E-mail: kimiye@sercomtel.com.br

\section{Resumo}

$\mathrm{O}$ artigo analisa o processo de implantação das escolas para os povos indígenas no Paraná desde o século XVI e procura identificar as principais características dessas escolas. Aponta as principais dificuldades encontradas para a implantação da educação escolar indígena proposta pelo MEC/LDB/Referencial Curricular Nacional para as Escolas Indígenas, em consonância com a Constituição Federal que garante aos índios o direito de serem e manterem-se como sociedades diferenciadas.

Palavras-chave: educação indígena; educação escolar indígena; educação intercultural e bilingüe

sta apresentação sobre a temática da educação escolar indígena, pretendo colocar algumas questões sobre a experiência dos povos indígenas desde que as escolas foram implantadas, a partir do século XVI. Dentro do contexto da história recente dos povos indígenas é que podemos refletir sobre a educação escolar indígena e os diversos sentidos que ela encerra. As escolas foram impostas pelos europeus, que aqui

\footnotetext{
' Este trabalho é uma versão ampliada de texto apresentado na $22^{\mathrm{a}}$ Reunião Brasileira de Antropologia. UNB/Brasília, DF. De 16 a 19 de julho de 2.000. Este artigo sintetiza oito anos de observação e pesquisa sobre a educação escolar indígena no Estado do Paraná.
} 
vieram com o objetivo de incorporar este continente ao seu domínio econômico-político-cultural. À conquista militar sucederam-se processos de dominação espiritual e ideológica, através da catequese e escolarização.

O que estou querendo dizer é que as escolas foram implantadas pelos conquistadores e tinham como objetivo garantir a domesticação e a domesticidade dos povos vencidos. Em grande medida, as escolas indígenas de hoje ainda guardam esse caráter civilizatório e constitui um impasse de difícil solução, pois a instituição escolar pertence ao universo da sociedade ocidental.

A exposição está dividida em seis partes, as quais revelam as múltiplas facetas que expressam a complexidade dessa questão. Se no passado a escola foi imposta aos índios e foi responsável pela destruição dos seus valores, substituídos que foram por valores ocidentais e cristãos, hoje a escola é uma reivindicação da maioria dos povos indígenas, principalmente dos jovens, os quais querem entrar na modernidade nas mesmas condições dos outros brasileiros, contudo, essa escolarização não significa, na proposta deles, deixar de ser Guarani, Kaingang ou Xavante. A sociodiversidade deve e pode ser preservada como patrimônio nacional, e quanto mais a preservarmos tanto maior será a possibilidade de construirmos uma nova sociedade, mais democrática e com espaço para diversidade cultural, que é constitutiva deste país.

Nessa exposição, vou historiar o processo escolar indígena no Paraná e o seu significado, apresentando a complexidade do problema, que envolve dimensões múltiplas. Ao final, falarei sobre a educação escolar indígena na atualidade, sobre as principais mudanças ocorridas na relação do Estado com os povos indígenas a partir da Constituição de 1988, e sobre as orientações do MEC, regulamentadas na LDB e no Referencial Curricular Nacional para as Escolas Indígenas.

\section{Antiguidade dos Povos Indígenas e Sua Diversidade Cultural}

Vivem atualmente no Brasil mais de 200 povos indígenas falantes de, pelo menos, 170 línguas. Essa imensa sociodiversidade é quase desconhecida da maioria dos brasileiros. Aliás, quando se pensa nos povos indígenas, imagina-se que eles só vivem na Amazônia e no Parque Nacional 
do Xingu. A grande maioria dos paranaenses desconhece os povos indígenas que vivem no Paraná. Muitos nem sequer sabem que eles existem.

Os povos pré-colombianos já estão neste continente há pelo menos doze mil anos, conforme as pesquisas dos arqueólogos. Quando Cristóvão Colombo chegou à América Central e Pedro Álvares Cabral atingiu a costa do Brasil, ambos registraram a presença e os contatos com esses povos. Todos os estudantes conhecem as famosas cartas de Américo Vespúcio e de Pero Vaz de Caminha.

As denominações "América" e "Brasil" foram inventadas pelos europeus. Do século XVI até meados do XX, eles conquistaram dos índios quase a totalidade de seus territórios, implantando uma nova ordem social e cultural que chamamos de sociedade nacional ou moderna. As comemorações dos 500 anos em toda a América foram para festejar a conquista das terras indígenas e a fundação da América e do Brasil como extensões dos domínios europeus. Para os povos indígenas, no entanto, esses últimos 500 anos representam a perda de seus territórios e de sua autonomia. A chegada dos europeus produziu dolorosas experiências de escravidão, extermínio, perda de territórios, epidemias, sofrimento, miséria e toda sorte de humilhações. Na verdade, os povos indígenas não têm o que comemorar, mas estão refletindo como poderão organizarse para que, nos próximos 500 anos, possam conquistar um lugar mais digno na sociedade denominada moderna. O projeto de educação escolar para os povos indígenas está associado a essa luta.

Quando da chegada de Cabral à região que veio a se tornar o Brasil, estima-se que havia pelo menos cinco milhões de pessoas, constituindo cerca de 900 sociedades diferentes. Elas foram surpreendidas pela chegada dos europeus, que romperam suas histórias e mudaram o rumo de suas vidas. Muitos povos foram inteiramente exterminados e outros conseguiram, depois de sofrerem grande depopulação, sobreviver a todas as formas de conquista e hoje vivem esparsos no continente, rodeados de brancos por todos os lados, sempre correndo o risco de perder as poucas terras que ainda têm.

As mais de duzentas etnias somam pouco mais de 300 mil índios $(0,2 \%$ da população nacional). Na maioria são microssociedades, isto é, são demograficamente muito pequenas. Desse total, 83 (40\%) têm uma população de até 200 indivíduos; 39 povos têm apenas entre 201 e 500 
habitantes; 28 têm entre 501 e 1.000; 39 povos têm de um a cinco mil. Cinco nações - Guajajara, Sateré-Maué, Potiguara, Xavante e Yanomami - têm entre cinco e dez mil cada. Os Terena e os Macuxi têm de 15 a 20 mil, seguidos dos Kaingang e Ticuna, com pouco mais de 20 mil cada. A população Guarani é a maior, com 30 mil só no Brasil. Nas décadas de 1950 e 1960, alguns povos chegaram a ser considerados extintos ou em vias de extinção.

É preciso esclarecer que estes dados estatísticos são daquelas populações que vivem em reservas administradas pelo Estado. Não estão computados os grupos que vivem fora das reservas (chamados "desaldeados"), nas cidades ou na zona rural. Tampouco estão computados os grupos "isolados" (ainda sem contato) e os grupos "emergentes" do Nordeste, que antes viviam ocultos como "caboclos" e só agora começam a se tornar visíveis.

Outro fato pouco conhecido do grande público é que existem reservas indígenas onde coabitam dois ou mais povos diferentes. Muitas vezes os censos não mostram as etnias minoritárias, criando uma imagem que não é a real. Além disso, em algumas reservas convivem etnias diversas que foram inimigas no passado. É o caso dos Guarani, que foram obrigados pelo SPI a viver em reservas kaingang, onde são tratados como "hóspedes" e subalternos. Em todos os casos, essa situação multiétnica de uma reserva é produtora de tensões e conflitos.

Outro ponto importante a ressaltar é que as divisões territoriais indígenas seguem um código próprio que nada tem a ver com as divisões geopolíticas dos brancos. Há povos indígenas que vivem em vários estados e mesmo em vários países. É o caso dos Guarani, que vivem no Brasil (nos estados do Rio Grande do Sul, Santa Catarina, Paraná, São Paulo, Rio de Janeiro, Espírito Santo e Maranhão), na Argentina, no Paraguai e na Bolívia. Os Yanomami vivem tanto na Amazônia brasileira quanto na venezuelana. Os Makuxi e os Wapixana vivem no Brasil e na Guiana e os Kampa, no Brasil e no Peru.

Diante desta realidade, muitas vezes o Estado tem tido dificuldades para administrar os problemas que envolvem terras indígenas. Temos um exemplo dessa dificuldade surgida no Paraná, quando os Guarani de Ocoí perderam suas terras para o lago da barragem de Itaipu. O agrônomo da Itaipu Binacional não conseguia entender que o território dos Guarani ultrapassa os limites nacionais e não 
aceitava que as famílias vindas do Paraguai e da Argentina tivessem direito à indenização. Ele tinha uma lista nominal das famílias que foram deslocadas de Ocoí/Jacutinga à época do fechamento das comportas e, quase vinte anos depois, o técnico da Itaipu fez um outro levantamento nominal e constatou que $50 \%$ das famílias constavam da lista anterior e as demais vieram posteriormente do Paraguai ou Argentina. O que se pôde constatar é que o território guarani atravessa países e estados e a mobilidade das famílias se faz nesse grande território.

Outro exemplo ocorreu quando um grupo de quase 300 Kaingang formou uma aldeia na cidade de Chapecó em Santa Catarina. A maioria vinha de reservas do Estado do Rio Grande do Sul. A prefeitura de Chapecó considerava que era responsabilidade do Estado do Rio Grande do Sul resolver o problema e que a Fundação Nacional do Índio deveria devolvê-los para as reservas de origem. Novamente, os brancos não entendiam que o território kaingang começa no Estado de São Paulo e vai até o Rio Grande do Sul (e até o início deste século também incorporava o Norte da Argentina).

\section{Informações Básicas Sobre a Educação Indígena ${ }^{2}$}

Antes de começar a falar da escolarização formal de alunos indígenas, é importante esclarecer que todas as sociedades humanas possuem seus próprios processos de socialização das crianças. Os povos indígenas no Brasil são povos sem escrita, e a socialização se dá através da própria vivência em sociedade. Não há uma instituição especializada em transmitir conhecimentos técnicos ou de interesse da sociedade. Ailton Krenak (1989, p.5), índio da etnia krenak, nos explica como é essa educação.

Na nossa tradição, um menino bebe o conhecimento do seu povo nas práticas de convivência, nos cantos, nas narrativas. Os cantos narram a criação do mundo, sua fundação e seus eventos. Então, a criança está ali crescendo, aprendendo os cantos e ouvindo as narrativas. Quando ele cresce mais um pouquinho,

\footnotetext{
${ }^{2}$ Aqui estou falando de educação indígena, isto é, do sistema indígena de socialização dos seus membros.
} 
quando já está com seis ou oito anos, aí então ela é separada para um processo de formação especial, orientado, em que os velhos, os guerreiros, vão iniciar essa criança na tradição. Então acontecem as cerimônias que compõem essa formação e os vários ritos, que incluem gestos e manifestações externas. Por exemplo, você fura a orelha. Fura o lábio para colocar o botoque. Dependendo de qual povo a que você pertence, você ganha sua pintura corporal, seu paramento, que vai identificar sua faixa etária, seu clã e seu grupo de guerreiros. Esses são os sinais externos da formação. Os sinais internos, os sinais subjetivos, são a essência mesma daquele coletivo. Então você passa a compartilhar o conhecimento, os compromissos e o sonho de seu povo. As grandes festas se constituem em instantes de renovação permanente do compromisso de andar junto, de celebrar a vida, de conquistar as suas aventuras. Então a nossa tradição consiste, de maneira resumida, nesses eventos. A formação é isso.

As sociedades indígenas, portanto, sem terem desenvolvido a instituição escolar, estabelecem formas difusas de socialização de seus membros jovens, que se tornam adultos conforme o padrão idealizado. Melià $(1979$, p.10) diz

A educação de cada índio é interesse da comunidade toda. A educação é o processo pelo qual a cultura atua sobre os membros da sociedade para criar indivíduos ou pessoas que possam conservar essa cultura. Os sistemas indígenas pretendem produzir pessoas que sejam um "bom Paresí", um "bom Bororo", um "Xavante autêntico", com todas as suas características específicas. Para nós até parece que, por vezes, o ideal de um bom brasileiro é ser um "bom norte-americano", como assim de um camponês é fazer do filho um "bom doutor". Isso não quer dizer que todos os índios sejam iguais.

[...] A educação indígena permite, de fato, um alto grau de espontaneidade, que facilita a realização dos indivíduos dentro de uma margem de muita liberdade. [...] No índio, a norma não pode ser confundida com a repetição mecânica de atos.

Ao longo de toda a vida, o índio ensina e aprende cultura, e essa educação se relaciona com cada um dos aspectos da vida coletiva, em suas múltiplas dimensões. 
Para termos uma compreensão da diferença entre nossas relações sociais e culturais e as dos índios, podemos dizer que, quando produzimos, somos alienados de nossa produção e nos reduzimos à força de trabalho, isto é, somos coisificados; quem somos como pessoa, não interessa ao sistema, interessa, sim, apenas o que cada um de nós representa como força-de-trabalho. Nesse sentido, somos sempre descartáveis e podemos ser substituídos a qualquer momento, se o empregador assim entender. Os indígenas, ao contrário, ao produzirem, realizam-se como sujeitos de sua produção. Explicando melhor: quando um Kaingang vai caçar, ele vai com seu iambré (cunhado). Se ele é da metade kamé, o cunhado deve ser, necessariamente, da outra metade, um Kairu. Como todo o universo é classificado como Kamé ou Kairu e essas metades são opostas e complementares, então ele, o caçador kaingang, vai fazer a ceva para a caça do seu iambré e vice-versa.

O produto da caça deverá ser repartido conforme as regras estabelecidas culturalmente. Dentro dessa organização social, todos têm acesso aos produtos da caça, coleta e agricultura, sejam eles crianças, adultos ou velhos. Isso porque, pelas regras da reciprocidade parental, todos são ligados por direitos e obrigações. Fica claro então que, no ato de caçar, o Kaingang se realiza como pessoa da metade kamé, como pai, marido e parente, e materializa a sua rede de normas e padrões culturais kaingang. Na sociedade capitalista, a distribuição da produção é regida pelo mercado e, como a sociedade é dividida em classes sociais, o acesso aos bens depende do potencial aquisitivo de cada trabalhador.

Durante mais de dez mil anos, os povos indígenas viveram neste continente, segundo distintas cosmologias, onde homens, natureza e sobrenatural estão interligados e influenciam-se reciprocamente. Dentro dessa visão de mundo, respeitaram a natureza e a preservaram através da elaboração de complexos e sofisticados sistemas de manejo do meio ambiente e seus ecossistemas.

\section{Breve Histórico da Educação Escolar Indígena no Paraná}

As reduções jesuíticas no Paraná: primeira experiência escolar As primeiras experiências indígenas de educação formal 
começaram nas reduções jesuíticas há quase 400 anos. A educação formal foi instituída tanto nas reduções jesuíticas dos séculos XVI e XVII quanto nas escolas dos aldeamentos dos séculos XVIII e XIX. Nas reduções espanholas, já se traduziam textos em língua indígena. Os missionários aprendiam a falar a língua dos grupos reduzidos, que não eram apenas de índios guarani (MONTOYA,1985, p.167).

Nos colégios das reduções, onde os missionários ensinavam crianças e jovens índios a ler e escrever, ensinavam-lhes também a tocar instrumentos musicais e a desenvolver atividades profissionais como de carpinteiro, ferreiro, alfaiate, tecelão, sapateiro e outras. Podese dizer que a educação que se fornecia aos jovens índios nas reduções era integral. Além disso, o ensino era ministrado na língua dos nativos ${ }^{3}$ (MONTOYA, 1985, p.167-168). Mesmo havendo interpretações positivas sobre a obra dos jesuítas, é preciso sempre reconhecer que tanto eles quanto os demais representantes das sociedades dominantes traziam em si um potencial destrutivo, porque o objetivo era claramente impor um modo de vida cristão e padrões da cultura ocidental. Falar a língua dos índios e conhecer aspectos de sua cultura eram apenas meios para obter sucesso na missão evangelizadora que cumpriam. Mas, principalmente, os índios eram treinados como mão-de-obra utilizada nas reduções e, mais tarde, nos aldeamentos.

O número de grupos guarani era maior, mas houve também a redução e escolarização dos ancestrais dos Kaingang (e certamente dos Xokleng), à época denominados Gualachos, Chiqui e Camperos (MELIÁ, 1979, p.12).

Os jesuítas foram os primeiros educadores das escolas para as crianças indígenas no Paraná. Analisando o método utilizado por eles, vemos que nele há muitos pontos em comum com o que se utiliza hoje, $40 \overline{0}$ anos depois. Podemos resumir algumas estratégias pedagógicas da seguinte forma:

- Uso da língua do grupo reduzido para que os ensinamentos (catequese e alfabetização) fossem melhor compreendidos. Padre Montoya (1985, p.67) registrou o seguinte:

\footnotetext{
${ }^{3}$ É interessante apontar que os missionários também ensinavam alunos de origem africana em sua língua de origem.
} 
- "E costuma haver, numa só cidade de espanhóis, índios de várias línguas, sendo com isso necessário que os padres as saibam para seu cultivo apostólico."

- A música como a primeira grande "motivação" pedagógica. Manoel da Nóbrega escreve em 1552: "Se viesse para cá algum tamborileiro e gaiteiro, parece-me que não haveria principal [cacique] que não desse os filhos para que lh'os ensinassem" (apud MAGALHÃES, 1951, p.11)

- Montoya complementa: "De modo notável são eles aficionados à música, que os padres ensinam aos filhos dos caciques, bem como a ler e escrever. Oficiam eles as missas com aparato musical, de dois a três coros. Esmeram-se em tocar instrumentos, tais como baixos, cornetas, fagotes, harpas, cítaras, guitarras, rabecas ('rabeles'), clarinetes ('chirimías') e outros. Ajuda isso muito em atrair os gentios e no seu desejo de nos levarem às suas terras, para educação e ensino de seus filhos (MONTOYA, 1985, p.169).

- As crianças indígenas eram retiradas de suas aldeias e eram colocadas nas escolas das reduções. Isso se aplicava tanto aos meninos quanto às meninas.

- As escolas davam uma formação completa: catequese, ler, escrever, contar, cantar e tocar instrumentos musicais. Sobre as jovens indígenas diz Gabriel Soares, em 1587: "As moças deste gentío que se criam e doutrinam com as mulheres portuguêsas, tomam muito bem o cozer e o lavrar, e fazem todas as obras de agulha que lhes ensinam, para o que tem muita habilidade, e para fazerem coisas doces e fazem-se estremadas cosinheiras" (apud MAGALHÃES, 1951, p.14).

- Para tentar obter constância e maior rentabilidade no comportamento das crianças indígenas, os missionários instituíram o castigo (corporal), costume europeu e inteiramente desconhecido entre os povos indígenas. Este foi o fator que mais colaborou para que as crianças abandonassem as escolas, o que chamou muito a atenção dos missionários. Mais adiante voltaremos a discutir essa questão.

- Apesar de os documentos dos missionários descreverem com certo entusiasmo sobre a inteligência das crianças indígenas, 
de elogiarem suas formas de sociabilidade, a boa memória, a generosidade, a franqueza, a honestidade e o espírito de justiça, há também registros de que eram inconstantes, desatentos, falsos e ingratos.

- Os documentos relatam também os ritos de iniciação como parte integrante do processo educativo próprio de cada sociedade.

- Os missionários perceberam que o processo educativo indígena era essencialmente difuso, isto é, "não há função, como não há funcionário especializado na missão de educar: todos os membros do grupo exercem função educativa assistemática e permanente sobre os indivíduos mais jovens do grupo" (MAGALHÃES,1951, p.16).

Em vista disso, se tomarmos os depoimentos dos professores brancos que ministram aulas nas escolas indígenas na atualidade, podemos perceber que os problemas, em sua essência, continuam os mesmos. A maioria desses professores continua afirmando que os alunos índios são inconstantes, não mostram interesse e apresentam dificuldades na aprendizagem.

Nos aldeamentos do século XIX, os professores, todos brancos, não tinham nenhuma preocupação em fornecer uma educação bilíngüe, e muito menos intercultural: a política indigenista era assimilacionista (do ponto de vista cultural) e integracionista (do ponto de vista econômico). Desde o começo da história da sociedade brasileira, as políticas indigenistas tinham como alvo a "civilização" dos índios e isso só mudou com a promulgação da Constituição de 1988, que reconheceu o direito aos povos indígenas de viverem segundo suas especificidades socioculturais. A escola intercultural proposta pelo MEC-LDB continua sendo gestada e é ainda uma realidade incompleta.

\section{A educação Indígena na Região da Bacia do Tibagi no Século XX}

Segundo os relatórios sobre as escolas dos aldeamentos da região do Tibagi, tanto nos aldeamentos de São Pedro de Alcântara quanto no de São Jerônimo, as escolas atendiam crianças indígenas e 
nacionais, estas filhas dos funcionários que trabalhavam nos aldeamentos e na colônia militar e de moradores dos arredores.

O Relatório da Povoação Indígena de São Jerônimo, de 1923, por exemplo, relata que a Escola "General Rondon" (localizada na sede da povoação) funcionou regularmente durante todo o ano, com a freqüência média de 16 alunos entre janeiro e março, sendo cinco índios e 11 nacionais; de março a outubro teve freqüência média de 13 alunos - cinco índios e oito nacionais. De janeiro a março a escola teve uma professora, que depois foi substituída por outra. As crianças indígenas moravam distante da escola e recebiam uma refeição diariamente.

No núcleo denominado "Dr. Rodolfo de Miranda", a escola também funcionou regularmente durante todo o ano: de janeiro a outubro havia 12 alunos, sendo cinco nacionais e sete índios; de outubro a dezembro havia 17 alunos - nove índios e oito nacionais. Nesse ano sucederam-se dois professores. Também eram fornecidas refeições para as crianças indígenas.

No núcleo "Capitão Osório", a escola funcionou ininterruptamente durante todo o ano, tendo a média de frequiência de 11 alunos, sendo sete índios e quatro nacionais; de outubro a dezembro a freqüência caiu para nove alunos - cinco índios e quatro nacionais. As crianças índias também recebiam uma refeição diária.

No Relatório de 1926, da mesma povoação, há informações mais detalhadas e interessantes, que mostram aspectos que ainda hoje se verificam nas áreas indígenas. Lê-se por exemplo:

[...] podeis perfeitamente verificar que, os alunos índios domiciliados na Linha Colonial Indígena 'José Bonifácio' compareceram às aulas durante este ano até o mez de Outubro, declarando os mesmos, que não voltariam mais à Escola, visto não quererem aprender, de nada servindo os meus conselhos e os da professora, que diariamente com carinho lhes dava, mostrando aos mesmos, as vantagens que eles (indios escolares), hão de usufruir.

[...] Novamente vos pondero, que diante da resolução destes índios escolares, de nenhuma forma quererem freqüentar as aulas, julgo esta despeza, manutenção da professora, completamente supérflua" (RELATÓRIO... 1926, p.29). 
O Relatório fala, ainda, sobre a Escola do Posto Indígena Tibagy, que não funcionou por falta de professor, e da Escola "Dr. Rodolfo de Miranda", que funcionou apenas 10 meses porque o professor pediu demissão.

Se compararmos a situação atual da educação nas reservas indígenas, os problemas são bastante semelhantes aos que têm ocorrido durante todo este século: falta de professores, "desinteresse" e desistência das crianças indígenas de freqüentarem as aulas, precariedade de condições materiais, repetência. Mesmo aceitando que esses fatores sejam reais, eles não são, no entanto, auto-explicativos. Não há nenhuma consideração com relação às verdadeiras razões do abandono ou baixo rendimento dos alunos índios, fatores que, no meu entendimento, referem-se a questões relacionadas à natureza da educação e ao modelo pedagógico de cunho civilizatório, implantado nas áreas indígenas. $\mathrm{E}$ isso por uma razão simples: toda a política indigenista estava direcionada para a integração do índio ao sistema nacional e, para isso, propunha projetos socioeconômicos e culturais seguindo o mesmo modelo integracionista do século XVI.

\section{As políticas de educação formal: o Estado, as igrejas e as ONGs}

Ao longo desses cinco séculos, o Estado e a Igreja (católica) trabalharam, em consenso para "civilizar" os povos indígenas. No caso, "civilizar" e "catequizar" podem ser tomados como sinônimos: transformar o "índio" em "civilizado", isto é, dar-lhe uma cultura européia e cristã. A escola passa a ter o papel de mediar essa passagem do índio de um estado (de civilização) a outro. Mas o que estava em questão, para o Estado, era a passagem do índio à condição de trabalhador nacional. Nesse sentido, o indígena era pensado como um ser transitório que, aos poucos, seria "civilizado" e deixaria de ser índio.

No século XX, a educação escolar para os índios passa a ser exercida não mais pelos missionários, mas por professores leigos. $\mathrm{O}$ objetivo continua a ser a integração dos povos indígenas à sociedade nacional e sua inserção como "trabalhador nacional". A criação de "reservas indígenas" pelo Serviço de Proteção ao Índio (SPI) tinha dois objetivos explícitos: de um lado, confinar os índios 
em espaços físicos restritos e controlados e liberar terras para colonização; de outro, integrar os índios à sociedade nacional, através de projetos de agricultura e de educação formal, ministrada por leigos nas escolas das reservas.

Mais recentemente, o Summer Institute of Linguistics-SIL, com sede nos Estados Unidos, passou a desenvolver projetos de educação formal em áreas indígenas de vários países. Sendo uma instituição religiosa, o objetivo do SIL era converter os índios, e a formação dos monitores indígenas confundia-se com o processo de conversão religiosa, reforçando o caráter civilizador da escola.

Em 1970 foi fundada a Escola Clara Camarão, no Posto Guarita em Tenente Portela-RS, num grande convênio da FUNAI com a Igreja evangélica de confissão luterana e o Summer Institute of Linguistics para formação de monitores e técnicos agrícolas das áreas indígenas. A parte pedagógica ficou a cargo do SIL, que atuou e ainda atua em várias áreas indígenas no Brasil. Silva e Azevedo (1995, p.151) resumem a atuação do SIL da maneira que segue:

Com a chegada do Summer Insititute of Linguistics ao Brasil em 1956, o quadro se transformou apenas em seus aspectos mais superficiais e visíveis. Caracterizado pelo emprego de metodologias e técnicas distintas das que se desenvolviam até então, o 'novo' projeto não escondia, como todos os seus predecessores, os mesmos objetivos civilizatórios finais. [...], o modelo de educação indígena desenvolvido pelo S.I.L. fez muitos aliados e arautos nas universidades brasileiras.

Os objetivos do S.I.L., [...], nunca foram diferentes dos de qualquer missão tradicional: a conversão dos gentios e a salvação de suas almas. [...]. Neste quadro as línguas indígenas passaram a representar meios de "educação" desses povos a partir de valores e conceitos 'civilizados'.

A Escola Clara Camarão, ao preparar e formar os professores indígenas e, ao mesmo tempo, convertê-los em cristãos, acabou por produzir um "personagem essencialmente problemático e ambíguo": um professor indígena "domesticado" e "subalterno" (SILVA; AZEVEDO, 1995, p.151). Esse modelo vigora até os dias atuais, e o SIL 
tem procurado atualizar seu papel civilizador e manter a subalternidade dos professores indígenas em encontros anuais, quase sempre patrocinados pela FUNAI e pelas secretarias de Estado.

O objetivo final da escola orientada pelo SIL não é a conquista da autonomia socioeconômica e cultural de cada povo e não está comprometida com a recuperação de sua memória histórica nem com a reafirmação da identidade étnica e cultural dos grupos envolvidos ou com o estudo e a valorização da própria língua e etnoconhecimentos, como prevê o MEC. O bilingüismo dos missionários do SLL está voltado para o domínio da língua indígena como forma de se territorializarem no universo do outro e, "de dentro", levarem aos indígenas o acesso à Bíblia, traduzida em língua nativa. Todos sabemos o que significa a conquista espiritual. No sentido que estamos mostrando, o bilingüismo nas escolas indígenas do Sul do Brasil guarda suas raízes históricas na política de "civilização" dos índios que foi implantada no século XVI. Romper com essas raízes parece ser o grande desafio no processo de implantação de uma escola indígena que seja, de fato, intercultural.

O bilingüismo implantado nas escolas indígenas do Sul foi caracterizado por Veiga e D'Angelis (1995) [...] como "bilingüismo de substituição", isto é, a criança começa a ser alfabetizada na língua indígena na primeira série. A partir da segunda série, o português vai sendo ensinado e passa a substituir a língua indígena até que esta seja eliminada.

Se nos primórdios da colonização dos povos indígenas era a Igreja católica que estava atrelada ao Estado e cuidava da educação escolar indígena, no século XX, muitas missões religiosas começaram a entrar nas reservas, com autorização do SPI e da FUNAI, para desenvolver ações nas áreas de educação e saúde, sempre tendo como objetivo último a conversão dos índios. Registra-se também, nos últimos 20 anos, a emergência de muitas ONGs interessadas em ações nas áreas indígenas, incluindo, em especial, o interesse pela implantação da educação escolar. Muitas dessas ONGs são vinculadas a universidades, mas há outras independentes e, de qualquer maneira, seus membros são profissionais que dependem de financiamento público e/ou externo. Portanto temos hoje, espalhados pelo Brasil, 
projetos de educação indígena desenvolvidos por vários tipos de instituições e com resultados os mais variados.

\section{O Modelo "militarizado" das Escolas Indígenas no Paraná: Algumas Considerações}

Um ponto que merece uma profunda reflexão, já colocado por Magalhães no início do texto, é a questão do castigo e o autoritarismo das escolas formais, método desconhecido nas sociedades indígenas e introduzido pelo conquistador branco.

Dentre as observações feitas pelos professores indígenas, uma delas diz respeito ao fato de que os professores brancos que ministram cursos nas escolas kaingang utilizam métodos autoritários nas salas de aula. São citados os termos "gritar" e "ralhar" com as crianças, como se assim elas pudessem aprender. Isso, segundo os professores índios, deixa as crianças com muito medo, humilhadas diante dos colegas. Os pais dos alunos, por sua vez, sentem-se igualmente ofendidos, pois na educação indígena as crianças jamais são castigadas. Essa é uma questão que merece uma discussão aberta nos cursos de preparação dos professores. A desistência de muitos alunos pode estar relacionada, como esteve nas escolas jesuíticas, ao castigo e autoritarismo próprio do branco, cuja sociedade é baseada em relações de dominação. O modelo implantado pelo SPI ainda está em vigor em muitas escolas indígenas e os avanços das teorias pedagógicas não chegaram até elas.

Em algumas escolas indígenas do Paraná, sabe-se que ainda se utilizam métodos militares, herança do SPI, no qual se prima pela disciplinarização das crianças. Como não há contestação por parte dos alunos, essas instituições são consideradas por alguns indigenistas como escolas-modelo. Nosso entendimento é exatamente o contrário. Esse modelo desconhece e desrespeita a cultura indígena e serve para submeter os índios ao domínio do branco. Nesse tipo de escola, não se ensina cidadania nem se contribui para criar uma sociedade multicultural. É destrutiva da cultura, da identidade étnica e da auto-estima, contribuindo para a manutenção do preconceito. 


\section{A Sociodiversidade Indígena no Paraná: Complexidade e Heterogeneidade}

Hoje vive no Paraná uma população indígena de mais de 10 mil pessoas. A grande maioria, aproximadamente $80 \%$, pertence à etnia kaingang. Em seguida, pela ordem decrescente, temos os Guarani, com 20\%. Os Xetá, um grupo de língua tupi-guarani, somam 10 indivíduos, não constituindo, entretanto, uma comunidade própria, por viverem separados uns dos outros desde que foram retirados de seu território (atual município de Douradina) quando eram ainda crianças. Os Xetá vivem, atualmente, em reservas indígenas com outros grupos étnicos e casaram-se, por força das circunstâncias, com pessoas de outra etnia, indígena ou branca. Alguns preferiram viver na cidade.

O Paraná, assim como muitos outros estados, apresenta reservas indígenas onde há convivência, nem sempre pacífica, de mais de uma etnia. Isso é resultado de políticas do SPI que, em última instância, gerenciava a questão indígena em sintonia com a ideologia desenvolvimentista do Estado. A justificativa para a constituição dessas reservas era, explicitamente, liberar terras para colonização branca.

Nesse sentido, as populações kaingang, que dominavam a maior parte das terras do Sul, nos séculos XIX e XX, foram confinadas em pequenas parcelas de seus antigos territórios. Os povos guarani, dispersos e trabalhando nas fazendas e olarias da região, foram, num processo ainda não estudado devidamente, incorporados nas reservas originalmente de índios kaingang. É o caso dos Guarani das reservas São Jerônimo (município de São Jerônimo da Serra), Laranjinha (município de Santa Amélia) e Pinhalzinho (município de Tomazina). Hoje, nestas duas últimas, praticamente não há famílias kaingang. É o caso também das Áreas Indígenas Mangueirinha e Rio das Cobras. Nas três primeiras as parcialidades são Guarani Ñandeva e Kayová, nas duas últimas são Mbyá.

Também há casos de reservas criadas especificamente para os Guarani, nas regiões em que eles não se dispersaram ou para as quais foram deslocados compulsoriamente. São as Áreas Indígenas Rio de Areia I e II (município de Inácio Martins), Ocoí (município de São 
Miguel do Iguaçu), Cotinga (município de Paranaguá) e Añetete (município de Diamante do Oeste).

No caso dos indivíduos xetá que vivem separados em diversas áreas, alguns inclusive na cidade, não se criou uma reserva quando foram contatados. Por serem menos de uma dezena e viverem separados, coloca-se uma questão crucial: considera-se que não formam mais uma nação porque não possuem terra própria e não vivem juntos, ou podese considerá-los como um povo sem território?

Outro ponto a se discutir, e que é consequiência também das políticas de reservar na mesma área várias etnias, é o surgimento de casamentos interétnicos e de uma população mestiça que incluem, no Paraná, brancos, negros, Kaingang, Guarani, Xokleng, Fulni-ô e Xetá. Ora, essa população, embora se autodefina como "mestiça", de fato, enfrenta alguns problemas quando se coloca a questão de definição étnica ou quando a questão étnica é utilizada nas disputas internas. No caso do ensino da "língua indígena" na escola em áreas que apresentam maioria de alunos mestiços, qual a melhor forma de definir a língua a ser ensinada? Estes são alguns dos problemas pendentes e não discutidos de forma conseqüente.

\section{Anos 1980-90: \\ Diagnósticos Sobre a Escola Indígena no Paraná}

Uma importante pesquisa feita por Silvia L. B. Braggio (1989), junto às escolas kaingang de Guarapuava, apontava as principais características e limitações do processo escolar formal, evidenciando que os índios não estavam aprendendo a usar a língua escrita funcionalmente fora do ambiente escolar e conseqüentemente os brancos desempenhavam funções que deveriam ser dos índios.

A análise dos materiais de alfabetização mostrava que: a língua é fragmentada em sílabas, as palavras e sentenças são isoladas sem nenhum contexto; a forma precede a função; a seleção de textos não é orientada para o conteúdo; forma e decodificação têm primazia sobre o conteúdo; as "histórias" não têm nenhuma relevância sociocultural; informações explícitas e implícitas não são balanceadas; não há organização do texto com desenvolvimento de personagens, locais, temas, etc.; a língua é controlada e artificial. 
Entre outras consequiências no processo de instrução, Braggio detectou problemas de compreensão, descontinuidade entre escola e ambiente familiar e, conseqüentemente, descontextualização na transferência das crianças de suas famílias para a escola; a falta de coesão nos "textos" dificulta a compreensão, porque não se aplicam estratégias cognitivas (inferências e predições). Em vista de tal quadro, Braggio (1989, p.161-176) sugeriu quatro propostas:

a) o uso da combinação da abordagem sociopsicolinguística de alfabetização (através das atividades por elas geradas) com a filosofia de Paulo Freire (no que diz respeito ao papel do diálogo e conscientização);

b) inclusão dos usos e funções da língua escrita encontrados na comunidade como atividades iniciais no processo de alfabetização;

c) início do ensino do português como língua escrita no $1^{\circ}$ semestre do pré-primário juntamente com o Kaingang, como sugerido por Feitelson;

d) implementação/preparação de um programa para a comunidade adulta, com criação de materiais escritos desenvolvidos dentro da comunidade por autores locais, como tem sido sugerido por Wendell, num contexto mais adequado para que o desenvolvimento da escrita se efetive, dando origem a um processo de alfabetização para os adultos mais genuíno e de acordo com as necessidades que eles tenham da língua escrita.

Uma monografia de graduação em ciências sociais da Universidade Estadual de Londrina, realizada por Fabiana de Ávila Lemos em 1997, e uma dissertação de mestrado em etnomatemática kaingang, produzida em 1999 na UNESP de Rio Claro por Chateaubriand Nunes Amancio, ambas resultado de pesquisas realizadas junto à Área Indígena Apucarana, município de Londrina, observaram que os professores não-índios que ministram aulas na $3^{a}$ e $4^{a}$ séries não conhecem o universo sociocultural dos Kaingang e, por essa razão, não conseguem viabilizar um processo de educação intercultural e dialógico. Ao mesmo tempo, as crianças daquela área indígena chegam 
à escola falando apenas a língua kaingang e, portanto, não conhecem o universo do professor branco.

Um ponto importante a assinalar é que os professores nãoíndios acabam não entendendo as dificuldades dos alunos, não conseguindo, portanto, adaptar ou criar uma metodologia que torne o ensino mais eficiente. Já os professores indígenas, por compartilharem do mesmo universo cultural de seus alunos, acabam usando exemplos da realidade indígena em substituição aos exemplos dos livros que, em geral, foram produzidos para escolas nacionais. No caso citado por Lemos (1997, p.44), ela observou que o uso da taquara (presente no dia-a-dia dos Kaingang), e não do tecido (proposto na lição no livro didático de Matemática), "facilita o ensino e a capacidade de compreensão e o interesse dos alunos são ampliados". A maior parte dos exemplos de matemática nada tem a ver com a realidade dos índios e, enquanto não se produz material didático próprio, os professores têm de adaptar os conteúdos para exemplos da realidade da comunidade. Daí a importância de o professor conhecer o universo sociocultural do educando. Todos os professores entrevistados por Lemos colocaram a falta de material didático adequado à realidade histórica e cultural de sua comunidade como o maior problema na sala de aula.

Outra questão levantada por Lemos é que a escola adota o calendário e os programas de acordo com o modelo branco. A adaptação do calendário respeita a época da colheita, que deve coincidir com o período de férias. No entanto, essa adaptação é a mesma utilizada pelas escolas nacionais rurais. Quando se trata de comunidade indígena, há que se levar em conta os costumes de cada sociedade. No caso kaingang, as famílias se deslocam esporadicamente para a cidade de Londrina, onde permanecem por cerca de dez dias para vender artesanato. Com isso, as crianças preferem acompanhar os pais a ficar na aldeia e acabam sendo reprovadas por faltas. Esse é um ponto bastante difícil de ser contornado porque os critérios de funcionamento e avaliação ainda estão fundados num modelo de sociedade urbana e industrial. Lemos esclarece ainda que as disciplinas são fragmentadas (Português, Matemática, Geografia, História), ao passo que o conhecimento kaingang é integrado, isto é, não há uma compartimentalização entre os conhecimentos. Na cosmologia indígena, 
sociedade, natureza e cosmos encontram-se imbricados, indissolúveis e reciprocamente relacionados. Ora, se a educação formal deve partir da realidade do educando, o primeiro requisito deveria ser a preparação do professor branco para conhecer o universo sociocultural histórico da sociedade com a qual vai lidar. Este parece ser um dos fatores do insucesso das escolas indígenas.

A falta de material didático adequado parece ser uma decorrência natural dessa situação de desconsideração e desconhecimento do universo social indígena. Se o professor nãoíndio e os planejadores/coordenadores continuarem não estudando a realidade do outro, não há como produzir material didático intercultural. Em minhas pesquisas verifiquei que os professores índios têm produzido material didático, mas sem muita orientação técnica. O que se tem feito é copiar o modelo das cartilhas nacionais, substituindo as lições com palavras e frases que dizem respeito à realidade das comunidades, mas guardando todos os defeitos da escola nacional, ou seja, os "textos" não são contextualizados nem histórica nem culturalmente. E a interculturalidade, portanto, continua não se realizando.

\section{Que é a Escola Indígena Proposta Pelo Mec}

A mudança constitucional produziu algumas consequiências. Uma delas foi o fato de o MEC ter assumido a responsabilidade pelas escolas indígenas. Até então, elas estavam sob a responsabilidade técnica e administrativa da FUNAI. O MEC então elaborou em 1993 a LDB para as escolas indígenas e em 1998 apresentou um grande documento denominado Referencial Curricular Nacional para as escolas indígenas, que especifica e detalha os princípios que já estão na Lei de Diretrizes e Bases.

Analisarei alguns pontos para problematizar a questão, iniciando pelo item 3.6 das Diretrizes para a Política Nacional de Educação Escolar Indígena, do $\mathrm{MEC}$, que trata dos princípios gerais da escola indígena: "ela deve ser específica e diferenciada, intercultural e bilíngüe."

Grupioni (1991. p.109) identifica, entre os pontos positivos da nova $\mathrm{LDB}$, o seguinte: 
[...] Assegurou também às comunidades indígenas, no ensino fundamental, o uso de suas línguas maternas e processos próprios de aprendizagem, abrindo espaço para que a escola deixe de ser um instrumento de imposição de valores e práticas da sociedade envolvente, e forneça os elementos necessários para uma relação autêntica com outros segmentos da sociedade brasileira. Nem a língua indígena, nem os processos próprios de aprendizagem de cada comunidade indígena, devem competir com a escola formal, mas [deve] ser a base na qual ela deve ser edificada. (grifo meu)

Analisando as condições que os professores enfrentam hoje nas escolas, não parece haver diferença em relação às que já existiam em 1984. Pode-se dizer que alguns textos "históricos" produzidos pelos professores locais através da memória dos velhos têm trazido melhora do material. Mas ainda predominam textos (também produzidos pelos professores) descritivos, acríticos e descontextualizados, porque não se instituiu de fato a nova LDB.

Nas Diretrizes para a Política Nacional de Educação Escolar Indígena (BRASIL, 1994), o item IV (Normas e Diretrizes) afirma:

um dos aspectos relevantes para a definição do currículo de uma escola é o conhecimento da prática cultural do grupo a que a escola se destina, já que essas práticas é que definem determinadas estratégias de ação e padrões de interação entre as pessoas, que são determinantes no processo de desenvolvimento do indivíduo.

Isto requer "uma intensa experiência em desenvolvimento curricular" e também "métodos de investigação e pesquisa para compreender as práticas culturais do grupo". Daí a necessidade da:

formação de uma equipe multidisciplinar constituída por antropólogos, lingüistas e educadores, entre outros, de maneira a garantir que o processo de ensinoaprendizagem se insira num contexto mais amplo do que um processo paralelo e dissociado de outras instâncias de apreensão e compreensão da realidade. (BRASIL, 1994, p.14. grifos nosso). 
Preocupados com uma verdadeira mudança na educação indígena, Márcio Ferreira da Silva e Marta Maria Azevedo (1995, p.158) sustentam

[...] assessores e técnicos em educação escolar indígena não podem prescindir de lições fundamentais de teoria antropológica e de etnologia sul-americana. Caso contrário, os programas de educação escolar indígena poderão ser pautados por uma ideologia de indianidade genérica, onde noções como organizações sociais, costumes, crenças e tradições dos povos indígenas são desprovidas de um sentido mais profundo e tomadas como detalhes pitorescos. (grifo nosso)

Mais adiante, os autores esclarecem:

Especificidade e diferenciação são atributos necessários para uma escola indígena adequada, mas não são condições suficientes para uma escola indígena autônoma: é necessário ainda assegurar o direito dos povos indígenas a associarem verdadeirannente as suas escolas aos seus projetos de presente e futuro. Em outras palavras, é preciso assegurar que os povos indigenas tenham o controle efetivo de suas escolas. (SILVA; AZEVEDO,1995, p.160-161. grifo nosso)

\section{As Dificuldades de Implantar uma Escola Fundada nas Necessidades e Objetivos dos Povos Indígenas}

As dificuldades para implantar a escola indígena formulada pelo MEC são de várias ordens. De um lado, o próprio MEC não tinha técnicos preparados para escolas indígenas e levou tempo para formar o seu quadro de assessores, os quais, de início cuidaram de viabilizar publicações de textos de antropologia, história, direito indígena e outros que pudessem subsidiar os professores na sala de aula. Essas publicações são fundamentais, e qualquer profissional que queira entrar nessa área deveria começar pela leitura desse material.

Por outro lado, o MEC já encontrou escolas indígenas funcionando em quase todas as áreas indígenas, fundamentadas nos 
objetivos assimilacionistas previstos na constituição anterior. Portanto ao MEC caberia reformular a educação já implantada e, como em qualquer processo de mudança radical, encontrou resistência, tanto de ordem técnica (novos objetivos e métodos) quanto de ordem política (no interior do órgão indigenista cujos técnicos perdiam espaço e poder).

A rede de influências já consolidada pelas forças tradicionais da FUNAI, do SIL e de segmentos das universidades, não tem permitido a implantação da educação indígena proposta pelo $\mathrm{MEC}$, isto é, aquela realmente fundada na realidade dos povos indígenas e em suas reais necessidades. No entanto, há projetos em várias regiões do Brasil que vêm tendo sucesso nesse sentido.

No Paraná, a consolidação do modelo implantado pela Escola Clara Camarão continua vigorando. Mesmo com a atuação, por quase dez anos, do Núcleo de Educação Indígena da Secretaria Estadual da Educação do Paraná, os recursos aplicados em dezenas de cursos não resultaram em mudanças qualitativas. Apresentei um diagnóstico sobre a educação escolar indígena em 1995 no $10^{\circ}$ COLE (Congresso de Leitura do Brasil) em Campinas, o qual permanece válido até hoje.

\section{Para desenvolver um ensino intercultural o professor precisa compreender as especificidades culturais e históricas dos alunos}

Um dos pontos que estamos enfatizando sempre, e está na orientação do MEC, é a necessidade de compreender as especificidades socioculturais e históricas das sociedades com as quais se vai lidar. Não basta falar, genericamente, que os indígenas possuem uma organização social própria, têm concepções diferentes de religião e vivem num universo significativo estranho ao nosso. É preciso conhecer qual é essa organização, quais são os significados, as regras e os valores que orientam suas práticas cotidianas e rituais.

Tenho constatado que os professores, em geral, desconhecem a verdadeira história regional como também nada sabem sobre a cultura dos grupos étnicos com os quais trabalham. O material didático é o mesmo das escolas nacionais e a história que contam na sala de aula omite a presença indígena. Além disso, continuam a utilizar os livros 
que reproduzem a idéia do "vazio demográfico", conforme denuncia Mota (1994) em seu livro.

Percebemos que esses professores pouco ou nada conhecem sobre diversidade sociocultural e que consideram a desistência e a repetência dos alunos índios como "falta de interesse" dos próprios índios. E, mais, concluímos que o que está ocorrendo é falta de compreensão, por parte dos professores brancos, do índio como alteridade sociocultural e, por essa razão, eles não conseguem desenvolver uma "educação intercultural". O que há, de fato, é uma dominação e uma imposição do modelo branco de sociedade e de cultura, em que a relação estabelecida continua fundada no autoritarismo, na desigualdade e no preconceito. Por outro lado, constatamos que os professores indígenas, que conhecem a sua sociedade, também conhecem os problemas do ensino e até têm soluções para muitos deles. O que falta é diálogo intercultural e estabelecimento de uma relação de parceria entre os professores índios e os não-índios. Os técnicos em educação - pedagogos e outros profissionais de educação - ainda não perceberam que, para poderem desenvolver projeto de educação indígena, precisam, antes de qualquer coisa, conhecer (estudar) a história e a cultura daquele grupo específico que vai ser seu público-alvo.

\section{Material Didático tem de Ser Intercultural. QUEM PRODUZ o Material Didático?}

Em geral, nas experiências no Paraná, os coordenadores de projetos de educação indígena têm deixado para os professores indígenas a tarefa de produzir o material didático. Observando o produto final, verifica-se a falta da contribuição de lingüistas, antropólogos e outros profissionais estudiosos da cultura e história indígenas. Os textos aparecem, então, na sua forma bruta, sem nenhuma formalização e sem nenhuma transformação exigida pela LDB. É como se os coordenadores dos projetos entendessem que a forma tal como produzida pelos professores indígenas - os quais não possuem formação histórica, antropológica ou lingüística fosse mais "autêntica". 
Aqui é que o processo intercultural é imprescindível. Se o professor índio conhece a sua realidade e o profissional de educação (geralmente vinculado a uma universidade) conhece a realidade da educação formal, deve haver uma relação de troca cultural entre os dois segmentos. O material bruto deve ser transformado em conhecimento formal e o resultado será um produto dessa relação dialógica. Aqui haveria, necessariamente, uma transformação das pessoas envolvidas, um enriquecimento cultural intercambiado entre os segmentos e as categorias profissionais, haveria o (re)conhecimento mútuo das culturas em interação. Ora, fica claro que a responsabilidade da produção do material didático exige esse tipo de intercâmbio e só pode ser produto coletivo de especialistas de distintas culturas.

Ao que parece, a orientação dos técnicos brancos (coordenadores dos projetos) é que o professor indígena deve ir à comunidade (dele mesmo) para colher os dados e os levar para o espaço da escola, porque o professor índio já compartilha desse conhecimento. Dentro dessa orientação, o técnico branco permanece em seu gabinete, não lê a produção acadêmica sobre a história e a cultura do grupo ao qual se destina o projeto e continua ignorando o universo sociocultural do índio. E hoje não se pode mais dizer que não se tem produção acadêmica sobre os Kaingang. De 1994 para cá, muitas teses foram apresentadas sobre a cultura e a história dos Kaingang, dos Xokleng e dos Guarani. É certo que ainda existe muito a ser estudado, mas o que já foi produzido permite uma compreensão de suas cosmologias, organização social e história.

Contribuição importante é a pesquisa de Amancio em 1999. Formado em Matemática, o autor acabou enveredando pela etnomatemática kaingang, sob orientação de D'Ambrosio. Nessa pesquisa, conseguiu dialogar com a antropologia e pôde estudar o conhecimento matemático da comunidade kaingang, dentro da perspectiva indígena. Mais do que isso, Amancio contextualizou a dualidade da cosmologia e organização social kaingang e analisou as suas relações com o seu hábitat dentro de uma perspectiva histórica. Os professores de Matemática contam, portanto, com esse trabalho como subsídio para a discussão e (re)direcionamento do ensino dessa disciplina no contexto da cultura kaingang e de sua dinâmica. 


\section{Considerações Finais}

Os povos indígenas no Paraná acumularam várias experiências de educação formal ao longo de quase 400 anos de contato. Os documentos e relatos mostram que os caciques, desde o início, tiveram interesse em que seus filhos aprendessem os conhecimentos dos brancos. Mas os objetivos anti-índios dos colonizadores transformaram a escola num espaço de destruição dos valores e costumes nativos. Não se produziu o diálogo intercultural que, certamente, estava na proposta dos caciques ao mandarem seus filhos à escola.

Desde 1500 os povos indígenas tentam dialogar com o branco invasor e com ele fazer alianças no modelo ameríndio. A instituição das escolas, estranha às sociedades nativas, foi aceita por eles como uma forma de mútuo conhecimento. Essa escola, no ano 2000, ainda está por ser construída.

A constatação que podemos fazer a partir das nossas experiências junto aos alunos e professores é que continua havendo uma barreira cultural entre as duas categorias, a qual pode ser pensada como expressiva da incomunicabilidade entre duas sociedades diferentes. Não há diálogo cultural, não há troca de conhecimentos e não há, da parte dos professores brancos, interesse em conhecer a cultura da sociedade à qual pertencem seus alunos. $\mathrm{O}$ que os técnicos e professores brancos sabem sobre a educação tradicional da sociedade com a qual lidam? E sobre seus rituais, danças, cantos e outras atividades que se constituem como processos de socialização?

Podemos constatar também que há quase 400 anos os pais das crianças indígenas se interessam em que seus filhos aprendam os conhecimentos do branco. Quais são e onde se situam, então, os problemas?

Vários professores indígenas vêm tentando mostrar quais são, mas suas falas não encontram eco entre os educadores e administradores brancos. No caso do Paraná, não há dados sistematizados sobre a sociodiversidade indígena, nem histórica nem antropologicamente. Essa sistematização é o primeiro passo para que se dê visibilidade não somente à diversidade em si, mas, principalmente, para que se tenha um quadro da complexidade dessa realidade multiétnica. 
As pesquisas mostram que desde o século XVII os indígenas se interessaram em aprender o conhecimento dos brancos estrangeiros. Essa mesma curiosidade não tiveram os primeiros professores das escolas para os índios. Ao longo dos 500 anos, as escolas tentaram impor a cultura dos conquistadores até que, no início da década de 1990, foi reconhecido aos índios, pela Constituição, o direito de serem diferentes. As sociedades pré-colombianas buscaram, a duras penas, romper com todas as formas instituídas de dominação e violência contra seus modos de vida e de pensamento, para tentar entrar no terceiro milênio com dignidade e orgulho de serem eles próprios.

\section{Referências}

AMANCIO, Chateaubriand Nunes. Os Kaingang da Bacia do Tibagi: um estudo etnomatemático em comunidades indígenas. 1999. Dissertação (Mestrado em Educação Matemática) - UNESP, Campus de Rio Claro, Rio Claro.

BRAGGIO, Silvia L. B. Alfabetização como um processo social: análise de como ela ocorre entre os Kaingáng de Guarapuava, Paraná. In: CONGRESSO DE BRASILEIRO DE LINGUÍSTICA APLICADA, 2., 1989, Campinas. Anais... Campinas, 1989.

BRASIL. Ministério da Educação. Diretrizes para a política nacional da educação escolar indígena. 2.ed. Brasília, 1994.

GRUPIONI, Luis Donisete Benzi. A nova LDB e os índios: a rendição dos caras-pálidas Cadernos de Campo, São Paulo, Ano 1, n.1, 1991.

KRENAK, Ailton. Receber sonhos. Entrevista. Revista Teoria \& Debate, São Paulo, n.7, p.2-13, jun./ago./set. 1989.

LEMOS, Fabiana de Ávila. Estudo preliminar sobre a educação formal indígena no Paraná. 1997. Monografia (Bacharelado em Ciências Sociais) Universidade Estadual de Londrina, Londrina.

MAGALHÃES, LÚCIA. Notas para o estudo do conceito de educação indígena do Brasil. Rio de Janeiro : Of. graf. da Universidade do Brasil, 1951.

MELIÀ, Bartomeu. Educação indígena e alfabetização. São Paulo: Loyola, 1979. 
MONTOYA, Pe. Antônio Ruiz de.onquista espiritual feita pelos religiosos da Companhia de Jesus nas províncias do Paraguai, Paraná, Uruguai e Tape. Porto Alegre: Martins, 1985.

MOTA, Lúcio Tadeu. As Guerras dos Índios Kaingang. A história épica dos índios Kaingang no Paraná (1769-1924). Maringá: EDUEM, 1994.

SILVA, Márcio Ferreira da; AZEVEDO, Marta Maria. Pensando as escolas dos povos indígenas no Brasil: o movimento dos professores indígenas do Amazonas, Roraima e Acre. In: A temática indígena na escola novos subsídios para professores de $1^{1}$ e $2^{ }$graus. Brasília: MEC, 1995.

VEIGA, V.; D'ANGELIS, W. Bilingüismo entre os Kaingang: situação atual e perspectivas. In: CONGRESSO BRASILEIRO DE LINGÜÍSTICA APLICADA, 4., 1995, Campinas.

RELATÓRIO da Povoação Indígena de São Jerônimo. SPI. 1923.

RELATÓRIO da Povoação Indígena de São Jerônimo. SPI. 1926.

\section{Abstract}

This article analyses the process of the school implantation for indigenous people on Paraná State since XVI Century and searches identify the major characteristics from those schools. Appoint the main difficulties encountered for implantation the indigenous school education proposed by MEC/LDB/National Curricular Reference for Indigenous Schools, to agree Federal Constitution that guarantees for Indigenous people the right to be and to persist with different societies.

Key words: indigenous education; school education for indigenous; intercultural and bilingual education 